\title{
Quantitative Aspects of the Protection of Freeze-Dried Escherichia coli Against the Toxic Effect of Oxygen
}

\author{
By M. B. LION \\ The Israel Institute for Biological Research, Ness-Ziona, Israel
}

(Received 26 September 1962)

\begin{abstract}
SUMMARY
Various substances protect dry Escherichia coli against oxygen. The concentration of these substances in the bacterial suspension, necessary to achieve a given degree of protection, is a function of the concentration of the bacteria in the suspension. The protector seems to act in the dry state. The viability of freeze-dried bacteria, unexposed to oxygen, may also depend on the concentration of the bacterial suspension. A common mechanism is suggested to explain the dependence of killing on population density, both during freeze-drying and during exposure of dried organisms to oxygen. The viability of bacteria during freeze-drying and of dried bacteria exposed to oxygen are both markedly affected by the presence of certain substances such as serum albumin or Bacto-protone.
\end{abstract}

\section{INTRODUCTION}

Escherichia coli organisms, freeze-dried from distilled water, are extremely sensitive to oxygen and are very rapidly killed in its presence (Lion \& Bergmann, $1961 a$ ). Certain inorganic salts, some sugars, and thiourea and some of its derivatives can protect the organisms against the toxic effect of oxygen (Lion \& Bergmann, $1961 b$ ). This effect is further quantitatively explored here. It will be shown that these protective compounds act in the dry state. Some general aspects of the lyophilization of bacteria will also be discussed.

\section{METHODS}

The general methods for the preparation of bacterial suspensions, their lyophilization and the determination of their viability have been described (Lion \& Bergmann, 1961 $a, b)$. The strain of Escherichia coli used was the same as in the previous studies. The protective substances studied were: thiourea, sodium iodide, glucose.

\section{RESULTS}

Escherichia coli suspended in thiourea solution and freeze-dried is protected against oxygen (Lion \& Bergmann, 1961 b). When the bacteria, dried from distilled water, were exposed to oxygen and only then reconstituted in fluid containing thiourea, no protection occurred (Fig. 1). The necessity to preincubate the bacteria in the protective solution before freezing and drying was tested as follows: (1) The bacterial suspension was incubated in either glucose or thiourea solution for $30 \mathrm{~min}$. at room temperature $\left(25^{\circ}\right)$ before freezing. (2) A pre-cooled concentrated solution of either compound was added to a pre-cooled suspension of bacteria in water so 
that the final desired concentration of the compound and concentration of bacteria were obtained. The mixture was immediately frozen at $-80^{\circ}$; this process took less than $15 \mathrm{sec}$. There was no significant difference in the protective capacity of glucose or thiourea after either of these treatments (Fig. 2).

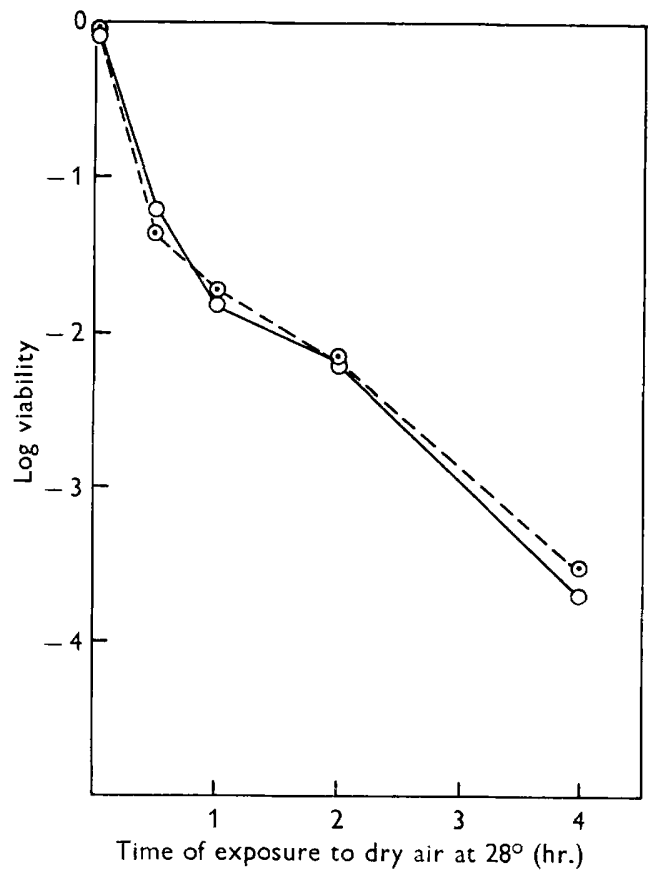

Fig. 1

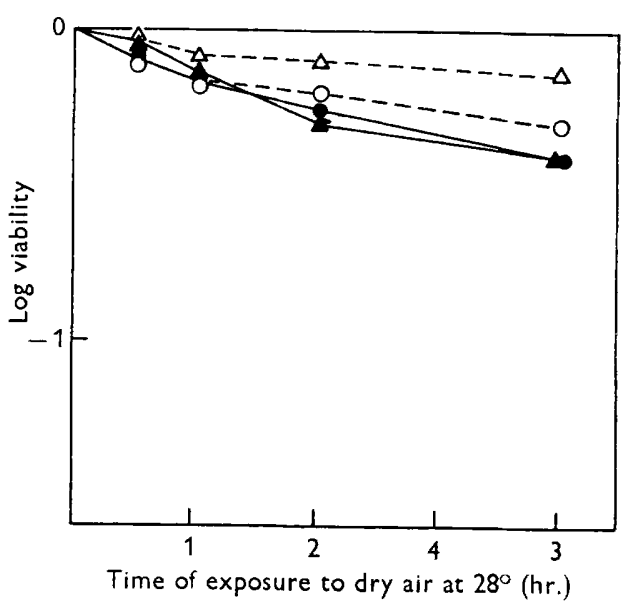

Fig. 2

Fig. 1. Effect of the resuspending medium on the viability of Escherichia coli cells, after freeze-drying from distilled water and exposure to air at $28^{\circ}$. $O$, Gelatin buffer; $\odot$, gelatin buffer $+2 \%(w / v)$ thiourea.

Fig. 2. Comparison between the effects of immediate freezing of the bacterial suspension in $0,1 \%(w / v)$ thiourea; $\triangle, 2 \%(w / v)$ glucose solutions and of preincubation in $\bullet$, $1 \%(w / v)$ thiourea; $\Delta, 2 \%(w / v)$ glucose before freezing on the viability of Escherichia coli cells freeze-dried in the presence of these substances and exposed to air at $28^{\circ}$.

A third experiment was made to see whether the protector against oxygen had to be present before freeze-drying, or whether it could be added in vacuum as a dry powder to the already dried bacteria and still show protective action. A suspension of bacteria in water was frozen on one side of an ampoule and a solution of thiourea frozen on the opposite side, so that there was no contact between the two patches. Some glass beads were added to the ampoules and the ampoules were freeze-dried and sealed in vacuum. The resulting powder was mixed in vacuum and only then exposed to dry air. No protection was detected. It is possible, however, that this finding is not conclusive, since such a mechanical mixing may have been insufficient to bring the bacteria and the protector into intimate contact.

Although direct evidence is lacking, indirect evidence that the protective substance can act in the dry state may be provided by testing bacterial suspensions of various concentrations in different concentrations of protective substance. In a liquid suspension each organism is independently exposed to the same concentration of 
protector, provided there is no change in the concentration of the protector by its diffusion into the organisms. If the protector therefore acted by preconditioning bacteria in a liquid suspension to a later resistance to oxygen when in the dry state, then the protective capacity should depend only on the concentration of the protector, but be independent of the concentration of organisms in the suspension. Three suspensions of different bacterial concentrations were tested in each of eight concentrations of three representative protective substances (sodium iodide, thiourea, glucose). Figures 3-5 are plots of the logarithm of the viability of dried bacteria exposed to air under standard conditions in the presence of the protective substances against the concentration of these compounds before freeze-drying. Each point is based on at least two samples. For each of the three protective compounds, the optimum concentration (i.e. that which assured highest viability) is seen to depend on the concentration of the bacterial suspension. In the range of suspension concentrations tested, and for each of the three compounds, the concentration of the protector needed for a given degree of protection seems to be roughly linearly related to the bacterial concentration in the protected suspension.

The concentration of the protective agent in the suspension did not change appreciably by diffusion into the suspended bacteria, even at the high bacterial concentration used. This was shown in the following way. In an earlier small-scale experiment not described here, we have found that a suspension of $1.6 \times 10^{10}$ bacteria $/ \mathrm{ml}$. is best protected in a $\mathbf{0 . 1 7 5} \%(\mathrm{w} / \mathrm{v})$ solution of NaI. The same concentration barely protected a suspension at $1.6 \times 10^{11}$ bacteria $/ \mathrm{ml}$. The following bacterial suspensions were prepared: (A) $1 \cdot 8 \times 10^{11}$ bacteria $/ \mathrm{ml}$. in $0 \cdot 1 \%(\mathrm{w} / \mathrm{v})$. This concentration was used instead of $0.18 \%$ in order to work in the vicinity of that part of the curve where protection decreases sharply with decrease in concentration (cf. Fig. 3). Any depletion of solute from the solution by the high concentration of bacterial suspension would thus be more easily detected. This suspension was incubated for $1 \mathrm{hr}$. at room temperature and a sample then dried and exposed to air under standard conditions. The rest of the suspension was centrifuged, the sedimented organisms discarded and the supernatant fluid was used to prepare suspension B. (B) $1.7 \times 10^{10}$ bacteria $/ \mathrm{ml}$. were suspended in the supernatant fluid of $\mathbf{A}$. The suspension was dried and exposed to air as before in $A$. (C) $1 \cdot 6 \times 10^{10}$ bacteria $/ \mathrm{ml}$. were suspended in a fresh solution of $0 \cdot 1(\mathrm{w} / \mathrm{v}) \mathrm{NaI}$, the suspension dried and then exposed to air. 'The results presented in Table 1 show that even at high bacterial concentrations in a comparatively low concentration of iodide (suspension $\mathbf{A}$ ), the concentration of the protective solute was not affected by the presence of the bacteria in the solution. These results provide some evidence that the protector can act in the dry state.

The decrease in protection at higher concentrations of protector above an optimum (indicated by broken lines in Figs. 3 and 4 ) is not due to loss of protective capacity of the compounds at these concentrations, as the killing observed under these conditions occurred already during freeze-drying and before any exposure to oxygen; this is shown in Figs. 6 and 7. Here the viability of the bacteria after freeze-drying in vacuum is plotted against the concentration of protective solute at different bacterial concentrations. The high mortality of bacteria freeze-dried at an iodide concentration exceeding the optimum for the given bacterial concentration occurred in the absence of oxygen and was therefore due to events during freeze- 


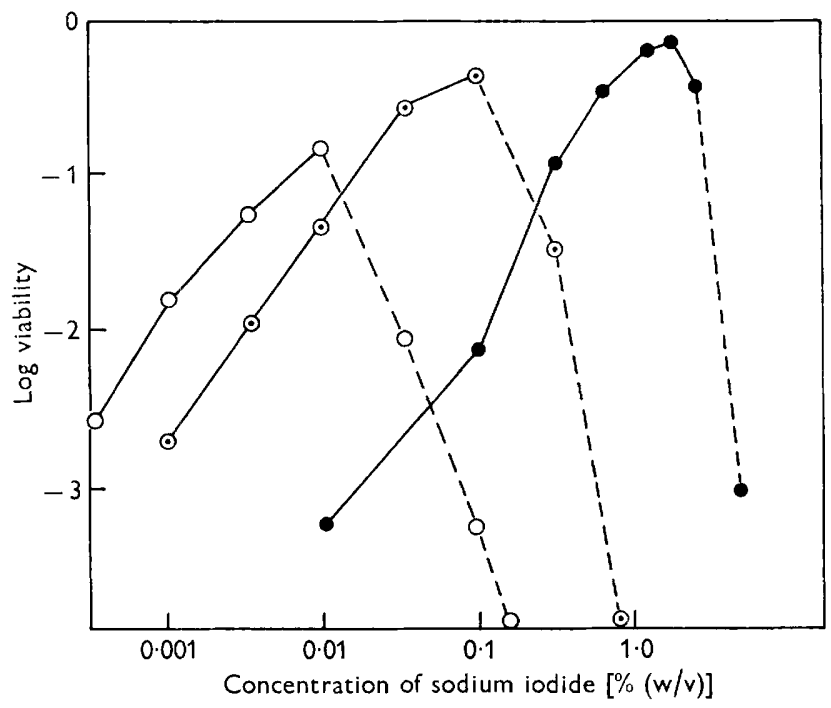

Fig. 3. Viability of Escherichia coli cells in suspensions of various densities freeze-dried in sodium iodide solution and exposed to air for $4 \mathrm{hr}$, at $28^{\circ}$, versus the concentration of sodium iodide in the solution., $1.6 \times 10^{11}$ cells $/ \mathrm{ml}$.; $\odot, 8.0 \times 10^{9}$ cells $/ \mathrm{ml}$.; $\bigcirc, 8.2 \times 10^{8}$ cells/ml.

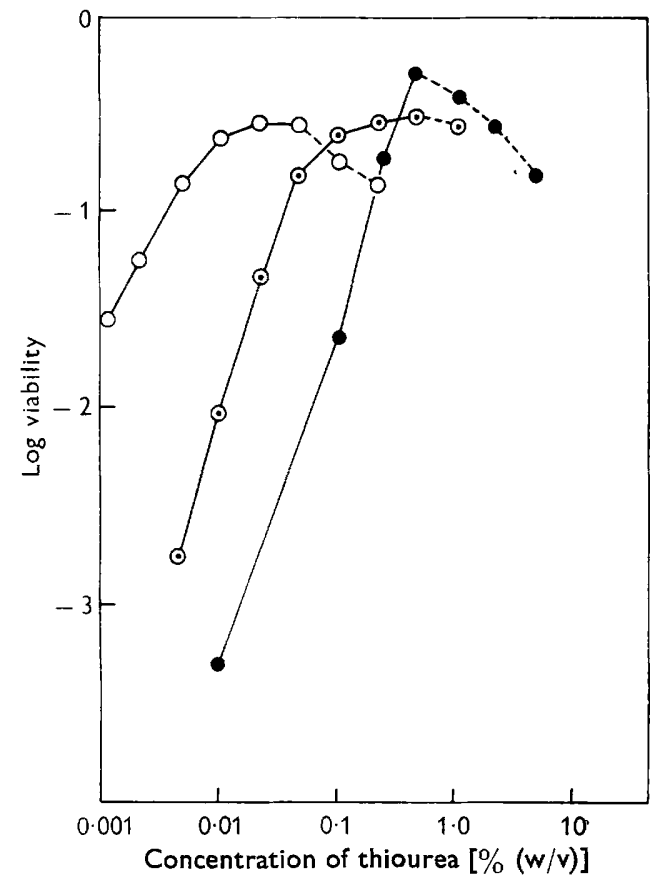

Fig. 4

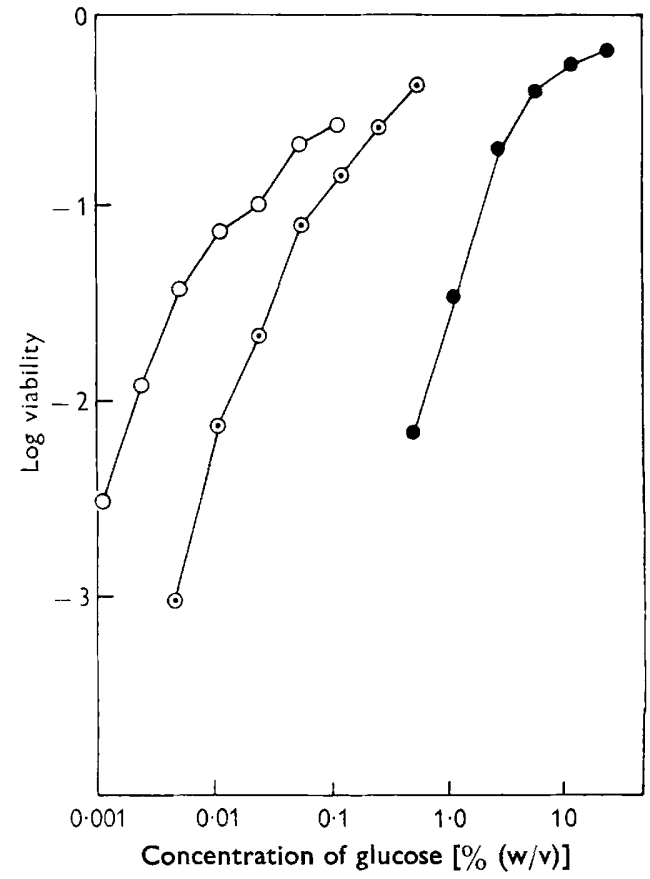

Fig. 5

Fig. 4. Viability of Escherichia coli cells in suspensions of various densities freeze-dried in thiourea solution and exposed to air for $4 \mathrm{hr}$. at $28^{\circ}$, versus the concentration of thiourea in the solution. $\odot, 1.7 \times 10^{11}$ cells $/ \mathrm{ml}$.; $\odot, 2.8 \times 10^{10}$ cells $/ \mathrm{ml}$. $\bigcirc, 2.4 \times 10^{9}$ cells $/ \mathrm{ml}$.

Fig. 5. Viability of Escherichia coli cells in suspensions of various densities freeze-dried in glucose solution and exposed to air for $4 \mathrm{hr}$. at $28^{\circ}$, versus the concentration of glucose, in the solution. $\bullet, 2.3 \times 10^{11}$ cells $/ \mathrm{ml}$; $\odot, 1.5 \times 10^{10}$ cells $/ \mathrm{ml}$; $\bigcirc, 1.4 \times 10^{9}$ cells $/ \mathrm{ml}$. 
drying proper (Fig. 6). Drying in excess of thiourea caused a much smaller degree of killing, while glucose even at the highest concentration tested was completely innocuous (Fig. 7).

Table 1. Viability of suspensions of Escherichia coli dried in $0 \cdot 1 \%(w / v) ~ N a I$ and exposed to air (atmospheric pressure) for $4 \mathrm{hr}$. at $28^{\circ}$

$\begin{array}{ccc}\text { Suspensions } & \begin{array}{c}\text { Absolute concentration } \\ \text { before drying }\end{array} & \begin{array}{c}\text { viability aft } \\ \text { exposure to } \\ \text { for } 4 \mathrm{hr} .\end{array} \\ \text { A } & 1.8 \times 10^{11} \text { bacteria } / \mathrm{ml} . & 1 \cdot 0 \\ \text { B } & 1.7 \times 10^{10} \mathrm{bacteria} / \mathrm{ml} . & 35 \\ \text { C } & 1 \cdot 6 \times 10^{10} \mathrm{bacteria} / \mathrm{ml} . & 44\end{array}$

For make-up of the different suspensions see text.

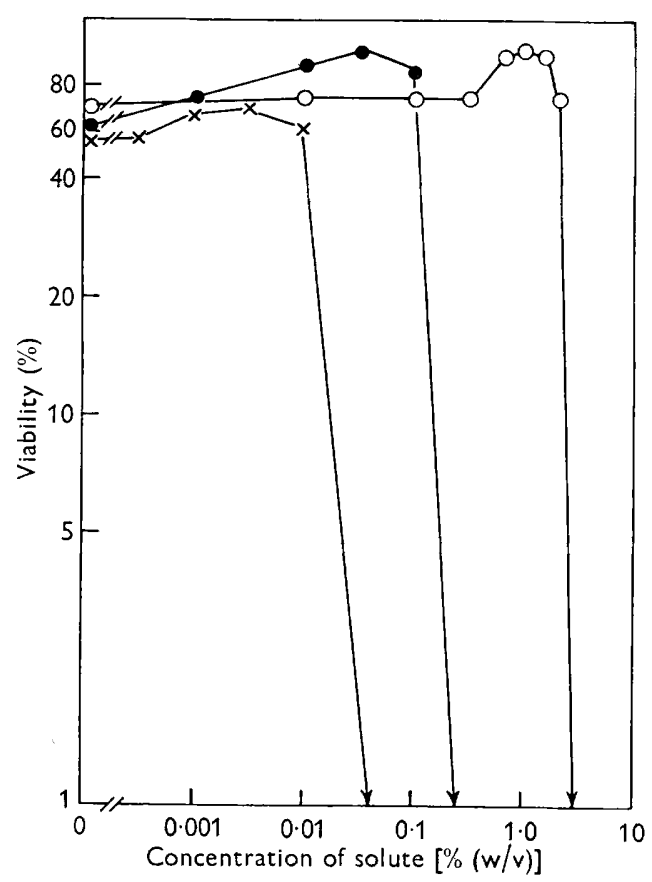

Fig. 6

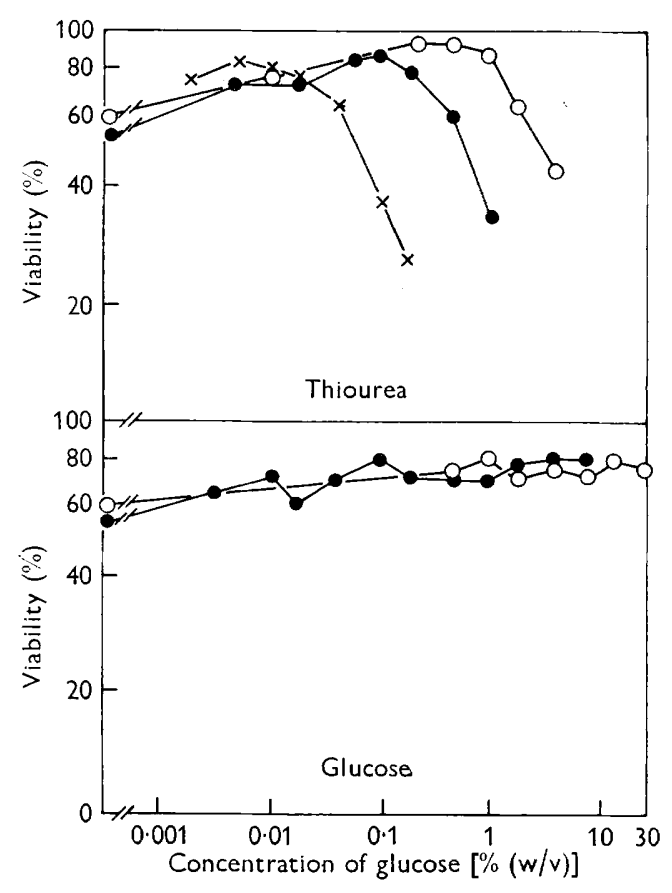

Fig. 7

Fig. 6. Viability of Escherichia coli cells in suspensions of various densities freeze-dried in sodium iodide solution and unexposed to air, versus the concentration of sodium iodide in the solution. $\bigcirc, 1.6 \times 10^{11}$ cells $/ \mathrm{ml}$; $\bullet, 8 \cdot 0 \times 10^{9}$ cells $/ \mathrm{ml}$. $\times, 8.2 \times 10^{8}$ cells $/ \mathrm{ml}$.

Fig. 7. Viability of Escherichia coli cells in suspensions of various densities freeze-dried in solutions of thiourea or glucose and unexposed to air, versus the concentration of these substances in the solution. Thiourea: $\bigcirc, 1.7 \times 10^{11}$ cells $/ \mathrm{ml}$.; $0,2.8 \times 10^{10} \mathrm{cells} / \mathrm{ml}$.; $\times, 2 \cdot 4 \times 10^{9}$ cells $/ \mathrm{ml}$. Glucose: $0,2 \cdot 3 \times 10^{11}$ cells $/ \mathrm{ml}$; $\bigcirc, 1.5 \times 10^{10}$ cells $/ \mathrm{ml}$.

For optimum protection against oxygen, it would appear that each bacterium in the dry state has to be surrounded by a certain amount of protector. If this be so, it should be immaterial how this state is achieved. The same relative survival would be expected, whether some of the bacteria added to the protective solution before the experiment were dead, or whether all the bacteria were alive, as long as the 
correct ratio between the amount of protector and the total number of bacteria were maintained. In presence of an excess of protector, addition of an inert 'diluting agent' such as dead bacteria, cell extracts, etc., in the proper amount, should be able to restore the optimum protective ratio. On the other hand, when such an optimum ratio already exists, the addition of any diluting agent should decrease the degree of protection below the optimum. These considerations are borne out by the experiments described in Table 2. A suspension of $c .10^{10}$ bacteria $/ \mathrm{ml}$. was dried in the presence of $\mathrm{NaI}$ or thiourea at two concentrations, one being optimum for $10^{10}$

Table 2. Viability of suspensions of Escherichia coli after exposure to air in the dry state for $4 \mathrm{hr}$. at $28^{\circ}$

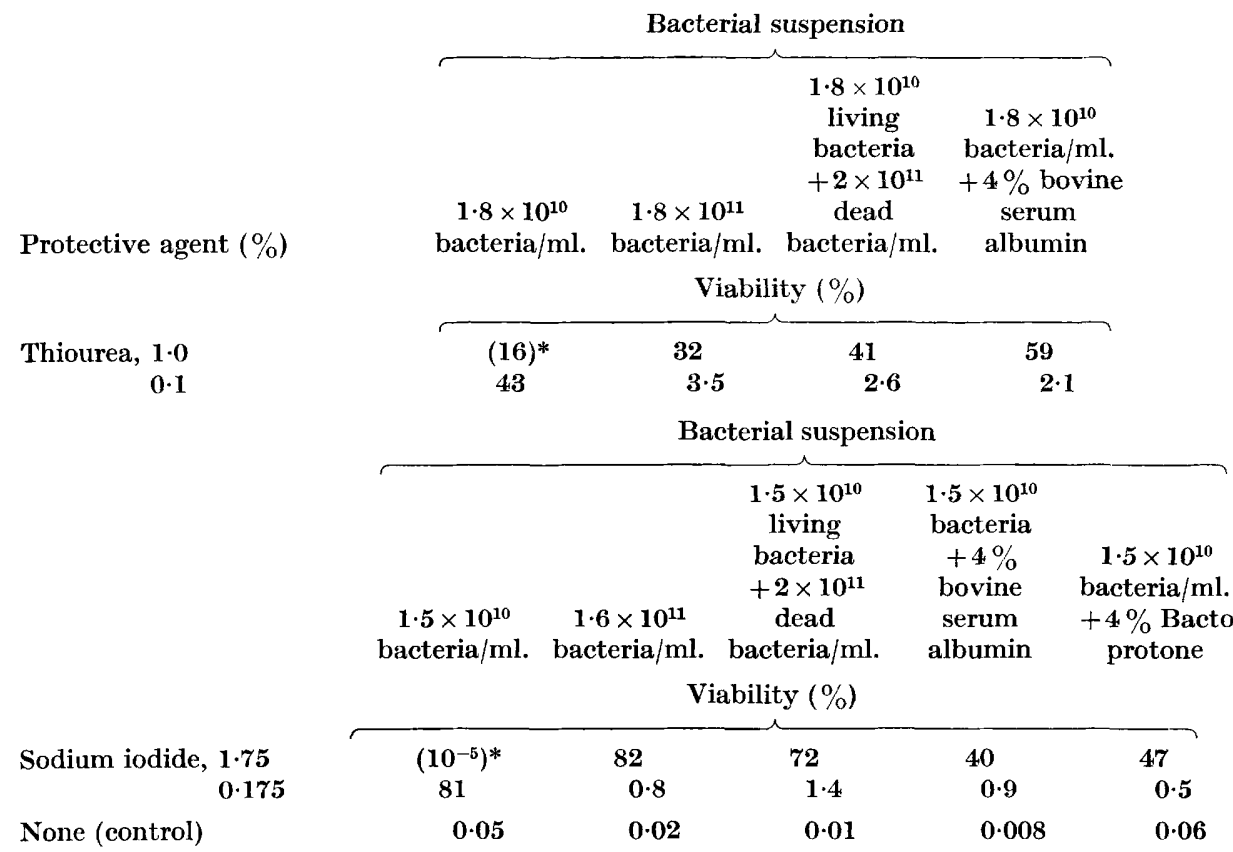

* Mortality occurred mainly during freeze-drying; see text.

bacteria/ml., the other being optimum for $c .10^{11}$ bacteria/ml., but constituting an excess for the test suspension. The dried preparations were next exposed to air. Three diluting agents were tested: (i) dead bacteria at a concentration of $c .10^{11} \mathrm{bacteria} / \mathrm{ml}$. (prepared by exposing dried Escherichia coli to air for $24 \mathrm{hr}$.); (ii) $4 \%$ (w/v) bovine serum albumin; (iii) $4 \%(\mathrm{w} / \mathrm{v})$ Bactoprotone, which is produced by Difco Laboratories Inc.; it is rich in higher proteoses but very low in free amino acids, some of which show protection against oxygen. The concentration of $4 \%$ for the last two materials was chosen because when dry it gives the same mass $/ \mathrm{ml}$. as $1.6 \times 10^{11}$ bacteria.

The first two columns in Table 2 are the controls in absence of diluting agent. Brackets around values indicate that the mortality was incurred mainly during freeze-drying in excess of solute (see Figs. 6 and 7 ); in all other cases mortality during freeze-drying was very small and the values represent the oxygen effect proper. The last row gives \% viability in the absence of protectors and proves that the diluting agents were really inert. 
Addition of the diluting agents to the suspensions of about $10^{10}$ bacteria $/ \mathrm{ml}$. caused this suspension to behave like one of about $10^{11}$ bacteria $/ \mathrm{ml}$. In the tests where excess of protector in the controls caused high mortality, the addition of dead bacteria, albumin or protone led to a marked improvement in viability. Under conditions in which originally optimum protection had been obtained in the controls, the viability decreased in the presence of the diluting agents, in agreement with the results obtained in the more concentrated (tenfold) suspension. Noteworthy are the results with iodide; the addition of dead bacteria, albumin or protone increased the viability of the organisms in $1.75 \% \mathrm{NaI}$ from $10^{-7}$ to nearly $50 \%$, while at the same time the viability in the $0.175 \%$ solution was decreased from $80 \%$ to about $1 \%$.

\section{.DISCUSSION}

The substances which protect freeze-dried bacteria against oxygen may act in one of the following ways : (i) They counteract the oxygen effect during the resuspension of the bacteria after the termination of the oxygen exposure. (ii) They directly interfere with the oxygen reaction in the dry state. (iii) They produce before freezedrying metabolic changes in bacteria such that bacteria become resistant to oxygen after drying. The most acceptable alternative would be the second. The addition of the protective agent only to the resuspending medium does not protect bacteria against the oxygen death. Bacteria are equally well protected when they are incubated in the protective solution for a long time, or when the solute is added only about $15 \mathrm{sec}$. before freezing. The diffusion of the protective solute into the bacterial cell required by the third alternative should therefore be completed in $15 \mathrm{sec}$. This in itself is possible (Cowie \& Roberts, 1955), but then the amount of the solute diffusing into the bacterial cell should be dependent only on the concentration of the solute and not on the concentration of the bacteria. Yet the bacterial concentration strongly affects the results. In the case of $\mathrm{NaI}$ this cannot be explained by the depletion of the protective solute from the suspension even at the highest bacterial concentrations.. Moreover, dead bacteria, as well as inert compounds, can replace live bacteria without affecting the results appreciably. The protective action occurs therefore probably in the dry state and a certain amount of protective material is required for each organism to prevent the reaction between oxygen and some bacterial receptor. Nothing can as yet be said about the nature of this reaction, but free radicals are probably involved (Lion, Kirby-Smith \& Randolph, 1961).

When bacterial suspensions are freeze-dried in $\mathrm{NaI}$ solutions exceeding a critical concentration, considerable killing occurs even without oxygen exposure. The critical concentration of $\mathrm{NaI}$ depends on the bacterial concentration. Freezedrying in thiourea affects the viability only to a small extent and in glucose not at all. NaI differs from the last two compounds in that solutions exceeding $c$. 1 м concentration are very toxic to bacterial suspension in liquid at $0^{\circ}$ (unpublished results). Freeze-drying of $8 \times 10^{9}$ bacteria $/ \mathrm{ml}$. in $0.5 \% \mathrm{NaI}$ solution causes a high mortality. If the same toxic effect in liquid suspensions is also responsible for the killing during freezing and drying, we have to suppose that the actual concentration of $\mathrm{NaI}$ during freezing and drying of $8 \times 10^{9}$ bacteria/ml. is much higher than the starting concentration. Physically this is actually to be expected. During freezing of the solution pure ice separates leaving behind a concentrated solution which solidifies 
only at the eutectic temperature $\left(-32^{\circ}\right.$ for pure NaI) (Luyet, 1960). Such concentrated solution will also form when a rapidly frozen solution is dried above the eutectic temperature. In both cases the bacteria probably remain in the unfrozen solution and are exposed to a high concentration of NaI. When now more bacteria are added to the same solution, a point is reached when the volume of the solution at the eutectic concentration is too small to submerge all the bacterial cells and the toxic effect will disappear. Thus the critical concentration of $\mathrm{NaI}$ is that starting concentration, at which the volume of the unfrozen part of the solution near the eutectic temperature is just large enough to submerge all or most of the organism in the suspension. This critical concentration depends on the bacterial concentration in the suspension. This point is illustrated by the following rough calculation.

The eutectic concentration of $\mathrm{NaI}$ is $390 \mathrm{~g}$./1000 g. solution (Intern. Crit. Tabl.). Its specific gravity is $c .1 .5 \mathrm{~g} . / \mathrm{ml}$. at $-\mathbf{3 2}^{\circ}$. In a suspension of $8 \times 10^{9} \mathrm{bacteria} / \mathrm{ml}$. in $0.5 \% \mathrm{NaI}$ there are $6 \times 10^{-13} \mathrm{~g}$. NaI/organism. At eutectic concentration the weight of the pool surrounding the organism is $1.5 \times 10^{-12} \mathrm{~g}$. and its volume is $1.0 \times 10^{-12} \mathrm{ml}$. Even for a spherical pool its diameter would be at least $1.2 \mu$ and in case of partial overlap between pools even larger than that. This would be enough to submerge all the bacteria in the suspension. When the starting concentration of $\mathrm{NaI}$ is now decreased to $0.1 \%$, or when the bacterial concentration is increased to $1.5 \times 10^{11}$ bacteria $/ \mathrm{ml}$, the average diameter of the pool surrounding each organism will be decreased by a factor of $1 \cdot 7$ and $2 \cdot 7$ respectively. The pool will then be too small on the average to submerge any single bacterium. There will be no difference if the increase in bacterial concentration is caused by live or dead organisms, or if an equivalent volume of the submerging pool is occupied by inert compounds such as serum albumin.

The accumulation of the solute round the bacteria assumed to be caused by freeze-drying might be a prerequisite for effective protection against oxygen in the dry state. This could explain the failure to achieve protection when dry bacteria were mixed with the dry protective compound before exposure to oxygen. Analogously, Gordy \& Myagawa (1960) obtained radioprotection of dry proteins by cysteine only when the two compounds were freeze-dried together, but not when they were mixed in the dry state before radiation.

Our results may also explain the so-called 'protective colloid' effect in freezedrying. Usually low concentrations of bacteria have been freeze-dried in isotonic solutions (Heckley, 1961). The resulting low viabilities were considerably improved by increasing the bacterial concentration, as in the case of Serratia marcescens and $\mathrm{NaCl}$ (Benedict et al. 1958). Similar results may be obtained by addition of high molecular substances, as shown in our experiments. This effect has been ascribed to some protective property of the colloid. Our studies suggest that there is nothing protective per se in colloids. On the contrary, when these substances are added to suspensions of bacteria freeze-dried in solutions containing the protector at optimum concentration, the viability of the freeze-dried bacteria exposed to oxygen will be decreased as compared to results without the colloid (cf. Table 2). If the role ascribed here to the protective colloid is correct, then no effect of the colloid would be expected when the bacteria are dried from distilled water. This is also demonstrated in Table 2. 
I wish to thank Dr A. Kohn for his continuous interest and his helpful criticism of the manuscript and Mrs Chana Herzberg for her excellent technical help.

\section{REFERENCES}

Benedict, R. G., Corman, J., Sharp, E. S., Kemp, C. E., Hall, H. H. \& J Jckson, R. W. (1958). Preservation of microorganisms by freeze-drying. I. Cell supernatant, Naylor Smith solution and salts of various acids as stabilizers for Serratia marcescens. Appl. Microbiol. 6, 401.

Cowie, D. B. \& Roberts, R. E. (1955). Permeability of microorganisms to inorganic ions, amino acids and peptides. In Electrolytes in Biological Systems. Ed. by A. M. Shanes. American Physiological Society Publishers.

GoRdy, W. \& Myagawa, I. (1960). Electron spin resonance studies of mechanisms for chemical protection from ionizing radiation. Rad. Res. 12, 211.

Heckley, R. J. (1961). Preservation of bacteria by lyophilisation. In Advances in Applied Microbiology, Vol. 3. New York: Academic Press.

Lion, M. B. \& Bergmann, E. D. (1961 $a$ ). The effects of oxygen on freeze-dried Escherichia coli. J. gen. Microbiol. 24, 191.

Lion, M. B. \& Bergmann, E. D. (1961 b). Substances which protect lyophilized Escherichia coli against the lethal effect of oxygen. J. gen. Microbiol. 25, 291.

Lion, M. B., Kinby-Smith, J. S. \& RandolPh, M. L. (1961). Electron-spin resonance signals from lyophilized bacterial cells exposed to oxygen. Nature, Lond. 192, 34.

LUYET, B. (1960). On various phase transitions occurring in aqueous solutions at low temperatures. Ann. N.Y. Acad. Sci. 85, 544. 